Check for updates

Montreal

Cite this as: $B M J 2022 ; 376: 0405$ http://dx.doi.org/10.1136/bmj.0405 Published: 16 February 2022

\title{
Covid-19: Mask mandates fall across US against public health advice
}

\section{Owen Dyer}

Indoor mask mandates are being abandoned in jurisdictions across the United States as politicians grappling with pandemic fatigue seek to restore a sense of normalcy, despite warnings from the US Centers for Disease Control and Prevention that the country is not ready.

"We continue to recommend masking in areas of high and substantial transmission," said CDC director Rochelle Walensky at a White House briefing. "That's much of the country right now, in public indoor settings."

The rate of new infections is plunging faster in the US than in Europe, but with just $64.4 \%$ of the US population vaccinated, the death rate is substantially higher. Over the past week, the country has lost about 43 people to covid per million population, compared with 26 in the European Economic Area. Only this week have clear signs emerged that the death rate too is now falling.

Most recent deaths in the US, however, are concentrated in regions under Republican governance with low vaccination rates, which either dropped mask mandates months ago or never had them. The current wave of loosening restrictions is largely a "blue state" phenomenon, led by Democratic governors and mayors in places that were hit hard in the early pandemic but are now highly vaccinated.

Nevada and New York state lifted indoor mask mandates last week. At the end of February, Illinois will lift a state-wide mask mandate, and Connecticut and Massachusetts will lift school mask mandates. Rhode Island, New Jersey, and Oregon will remove some or all masking rules in March. More such announcements are likely imminent.

"As best we can tell right now this thing is going from pandemic to endemic, and we feel it is the responsible step to take," said Governor Phil Murphy of New Jersey. A crushing first wave left his state with more deaths per capita than any other for much of the pandemic, but today that undesirable record is held by poorly vaccinated Mississippi. President Biden called the lifting of mask mandates "probably premature," but said that he understood people's frustration.

California lifted mask mandates everywhere except in schools on 15 February, but for vaccinated people only. How this rule will be enforced is not clear. Thousands of unmasked fans attended last weekend's Superbowl in Inglewood, California, although both state and local mandates were in force.

In several states, local governments have chosen to continue mandates despite the state lifting them. Santa Clara and Los Angeles counties said that they will not follow the rest of California in relaxing masking rules until they see less transmission and more vaccinations. Schools in Boston, Massachusetts, and New Haven, Connecticut, plan to keep mask requirements in place despite the decisions of their state governors.

The result is a bewildering patchwork of regulations across the country, made even more complex by active disputes between several Republican governors and their school systems. In Arizona, Iowa, and Texas, courts have halted state attempts to force schools to unmask. In Florida and Virginia, school systems have kept their mandates, but the governors have told parents that they may ignore them.

In some cases the rapid shift in policy seemed to collide with sterner policies put in place months ago. Even as New York state lifted its proof of vaccine requirement for entering indoor public spaces, New York City fired 1470 city workers who had refused vaccination, the largest mass firing for vaccine refusal yet seen in the country. About 3000 workers had been due to be fired under policies put in place last year, but nearly half of these opted instead for last minute vaccination.

\section{Vaccination of under $5 \mathrm{~s}$ put on hold}

Vaccination of children under 5 , which had been expected to begin this month, will now be delayed until at least April, after data from Pfizer-BioNTech's paediatric trial, shown to the CDC, found insufficient protection in this age group from two doses. The study is continuing with third doses, but the data have not yet been submitted. If a three dose regimen proves effective, vaccinations will begin on that basis. Each dose is much lower than an adult dose.

The US might advance its schedule of fourth adult doses (second boosters) after CDC data showed third doses losing some effectiveness against omicron after four months. ${ }^{1}$ The booster was $91 \%$ effective against hospital admission in the first two months, falling to $78 \%$ after four. Although still robust, this protection was lower than many experts had hoped.

Last week the US passed the milestone of one million excess deaths during the pandemic. The data showed a sharp rise in deaths from heart disease and hypertension, although these could be undiagnosed coronavirus infections, the CDC cautioned. On 15 February, deaths attributed to covid stood at 911145.

Centers for Disease Control and Prevention. New CDC studies: covid-19 boosters remain safe, continue to offer high levels of protection against severe disease over time and during omicron and delta waves. 11 Feb 2022. https://www.cdc.gov/media/releases/2022/s0211-covid-19-boosters.html

This article is made freely available for personal use in accordance with BMJ's website terms and conditions for the duration of the covid-19 pandemic or until otherwise determined by BMJ. You may download and print the article for any lawful, non-commercial purpose (including text and data mining) provided that all copyright notices and trade marks are retained. 